\title{
School Well-Being Siswa Sekolah Dasar dan Siswa Sekolah Menengah Pertama Pengguna Sistem Full-Day School di Indonesia
}

(Examining School Well-being among Elementary and Junior High School Student with FullDay School System in Indonesia)

\author{
Faizah Faizah*, Ulifa Rahma, Yuliezar Perwira Dara, Candra Laksmana Gunawan \\ Jurusan Psikologi, Fakultas Ilmu Sosial dan Ilmu Politik, Universitas Brawijaya, \\ Jl. Veteran, Malang, Jawa Timur, 64145 Indonesia \\ *corresponding author, e-mail: faizah_hermawan@ub.ac.id
}

Article received: October $18^{\text {th }} 2019$; revised: January $24^{\text {th }} 2019$; accepted: February $11^{\text {th }} 2019$

\begin{abstract}
Character Building Education in Indonesia has officially become a new regulation in the aspect of education therefore several state-owned schools have implemented a full-day system. The school system and the presence of student are complementary components, students' perspective upon themselves and the school environment as part of well-being fulfillment. The purpose of this study was to determine the state of school well-being of elementary school students and junior high school students who implemented the full-day system. This research was a comparative quantitative study with accidental sampling technique. This research was conducted in Malang, involving 285 students from five elementary schools and 275 students from three junior high schools as participants. The research instrument used was the School Well-being Profile (SWP). The data analysis using independent twosample t-test with Welchs t-test method. The results showed there were differences in school well-being in elementary and junior high school students in full-day systems. Elementary students have higher school well-being compared to junior high school students. Furthermore, the results of this study can be used as a reference to provide counseling services in improving school well-being of full day school students, especially junior high school students.
\end{abstract}

Keywords: school well-being; elementary school; junior high school; full-day system

\begin{abstract}
Abstrak: Pendidikan pembangunan karakter di Indonesia telah resmi menjadi peraturan baru bagi dunia pendidikan sehingga beberapa sekolah negeri memberlakukan sistem full day. Sistem sekolah dan eksistensi siswa merupakan komponen yang saling melengkapi, pandangan siswa terhadap diri dan lingkungan sekolah sebagai bagian dari terpenuhinya well-being. Tujuan dari penelitian ini adalah untuk mengetahui keadaan school well-being siswa Sekolah Dasar (SD) dan siswa Sekolah Menengah Pertama (SMP) yang menerapkan sistem full day. Penelitian ini merupakan penelitian kuantitatif komparatif dengan teknik sampling accidental sampling. Penelitian ini dilakukan di Kota Malang, dengan melibatkan 285 siswa dari lima SD dan 275 siswa dari tiga SMP sebagai partisipan. Instrumen penelitian yang digunakan yaitu School Well-being Profile (SWP). Analisis data menggunakan independent two-sample t-test dengan metode Welchs t-test. Hasil penelitian menunjukkan terdapat perbedaan school well-being pada siswa SD dan SMP sistem full day. Siswa SD memiliki school well-being yang lebih tinggi dibandingkan siswa SMP. Hasil penelitian ini dapat dijadikan acuan untuk memberikan layanan konseling dalam meningkatkan school well-being siswa sekolah full day khususnya siswa jenjang SMP.
\end{abstract}

Kata kunci: school well-being; sekolah dasar; sekolah menengah pertama; sistem full-day

How to cite: Faizah, F., Rahma, U., Dara, Y. P., \& Gunawan, C. L. (2020). School Well-being Siswa Sekolah Dasar dan Siswa Sekolah Menengah Pertama Pengguna Sistem Full-day School di Indonesia. Jurnal Kajian Bimbingan dan Konseling, 5(1), 34-41. https://doi.org/10.17977/um001v5i12020p034 


\section{PENDAHULUAN}

Sejak tahun 2017, siswa SD dan SMP dihadapkan dengan program pendidikan penguatan karakter (PPK), dimana kegiatan belajar mengajar (KBM) program ini dilaksanakan selama delapan jam sehari atau empat puluh jam selama lima hari dalam satu minggu yang secara umum dikenal dengan istilah full-day school. Secara ideal, penerapan full-day school diiringi dengan kesiapan satuan pendidikan, baik dari segi fasilitas maupun tenaga pendidik dan kependidikan (Indahri, 2017).

Sistem full-day school memiliki pengaruh positif terhadap prestasi akademik siswa jika sarana dan prasarana sekolah mampu disesuaikan dengan kebutuhan dan keadaan siswa, kurikulum dan guru (Soapatty \& Suwanda, 2014). Fasilitas yang dimiliki sekolah dapat memprediksi pencapaian akademik siswa dan tingkat kehadiran siswa di sekolah (Durán-Narucki, 2008), serta kesiapan tenaga pendidikan dan kependidikan bertujuan agar siswa dapat belajar dengan baik dan sejahtera di sekolah.

Di negara maju, anak-anak menghabiskan banyak waktu di sekolah selama tahap perkembangan mereka, dimana masa tersebut adalah masa ketika mereka mengalami perubahan fisik, sosial, dan psikologis yang penting (Ben-Aryeh, Casas, Frønes, \& Korbin, 2014). Anak-anak di Indonesia juga sama seperti anak-anak di negara maju, dalam artian akan menghabiskan lebih banyak waktu di sekolah yang menerapkan sistem full-day school pada masa perkembangannya.

Sebuah penelitian pada SD Sabbihisma yang telah melaksanakan full-day school selama lebih kurang 20 tahun membuktikan bahwa program full-day school mampu memberikan efek positif terhadap kemampuan dan perkembangan siswa, bahkan mampu menunjang keberhasilan penanaman nilai-nilai karakter pada diri siswa (Danil, 2018). Implementasi sistem ini ke siswa SD yang berada pada tahap perkembangan masa anak berbeda dengan siswa SMP yang telah memasuki tahap perkembangan remaja yang penting dalam membentuk school well-being siswa. Siswa SD tergolong pada masa anakanak menengah, masuk pada tahap perkembangan kognitif operasional konkrit dan tahap perkembangan Social Industry vs Inferiority (Santrock, 2012). Krisis pada tahap perkembangan ini dapat diatasi dengan mengembangkan kompetensi anak, seperti kompetensi siswa di sekolah, dan di bidang olahraga (Macnow, 2017).

Penerapan full-day school dengan kualitas manajemen pembelajaran yang baik, akan meningkatkan motivasi belajar siswa SMP (Rosalina, 2012). Motivasi merupakan bagian penting dalam membangun perkembangan diri dan akademik siswa SMP. Sebagaimana kita ketahui, Siswa SMP mulai memasuki masa remaja yang berada pada tahap perkembangan kognitif operasional formal dan tahap perkembangan Social Identity vs Role Confusion (Santrock, 2012). Hubungan sosial yang dibangun remaja merupakan salah satu cara remaja mengatasi krisis pada tahap ini dan membentuk identitasnya (Macnow, 2017). Pada masa remaja, proses berpikir siswa sedikit demi sedikit mendekati proses berpikir orang dewasa, yang mana lebih abstrak dan logis yang mungkin memengaruhi penilaian siswa terhadap lingkungan sekolahnya (Konu \& Rimpelä, 2002).

Di sisi lain, penerapan full-day school juga meningkatkan tingkat stres siswa karena durasi belajar yang lebih panjang (Susilawati, 2014), sedangkan salah satu tujuan sekolah adalah untuk meningkatkan kesejahteraan bagi anak untuk jangka panjang (Ben-Aryeh et al., 2014). Penelitian kaitan antara learning environment dengan emotional well-being, menemukan bahwa jadwal yang padat, kurikulum yang tidak realistis dan tuntutan akademis yang terlalu tinggi dan sulit akan memicu stres pada siswa serta beresiko menimbulkan kecemasan akademik (Tharani, Husain, \& Warwick, 2017).

Sistem full-day school dianggap hanya dapat memfasilitasi perkembangan kognitif siswa, namun tidak memfasilitasi perkembangan afeksi diri siswa (Kartika \& Herawati, 2012). Karena dampaknya yang kontradiktif bagi siswa, kesiapan tenaga pendidik, kependidikan, dan fasilitas diperlukan agar dapat memfasilitasi siswa untuk belajar dengan baik dan meningkatkan kesejahteraan siswa di sekolah. Hal-hal tersebut terdapat dalam konsep sejahtera dalam konteks sekolah yang dijelaskan oleh Konu \& Rimpelä, (2002) sebagai school well-being.

School well-being merupakan konsep mengenai berbagai faktor yang memengaruhi kesejahteraan siswa dengan tujuan untuk memenuhi kebutuhan dasar siswa di sekolah dari sudut pandang siswa (Konu \& Rimpelä, 2002). Komponen-komponen kesejahteraan dalam konsep school well-being dibagi dalam empat dimensi, yaitu having (kondisi sekolah), loving (hubungan sosial), being (pemenuhan diri), dan health (kesehatan). Keempat faktor tersebut saling berhubungan satu dengan yang lain membentuk konsep school well-being (Konu \& Rimpelä, 2002). 
Penilaian siswa terhadap lingkungan sekolahnya memengaruhi school well-being siswa. Terkait dengan school well-being siswa, sebuah penelitian menyebutkan bahwa siswa SD merasakan kondisi sekolah, hubungan sosial dan pemenuhan diri yang lebih baik daripada siswa SMP (Konu \& Lintonen, 2006). Pernyataan ini sesuai dengan hasil penelitian bahwa kepuasan hidup individu cenderung akan menurun pada masa remaja (Ben-Aryeh et al., 2014). Remaja juga merasa bosan pada sebagian besar waktu yang dihabiskan di sekolah (Ben-Aryeh et al., 2014). Sebuah analisis penelitian menemukan bahwa full-day school dalam perspektif sosial tidak semuanya baik, karena siswa yang menghabiskan waktu dengan durasi panjang di sekolah dapat mengganggu intensitas interaksi siswa (Sahari, 2018). Padahal siswa juga butuh interaksi dengan teman-teman sebaya di sekolah, teman sebaya di lingkungan tempat tinggal, dan juga keluarga di rumah.

Siswa yang bersekolah sehari penuh, kurang memiliki waktu untuk bermain dan mensosialisasikan pribadi (Sahari, 2018). Ketika sampai di rumah pada sore hari, mereka merasa capek, sehingga tidak sempat berkunjung ke rumah teman untuk bermain. Hal tersebut mengakibatkan kurang terlatihnya jiwa sosial terhadap lingkungan rumahnya, karena teman yang dimilikinya hanya teman di sekolah, sehingga kurang dapat bersosialisasi terhadap lingkungan masyarakat. Beberapa remaja bersosialisasi untuk mengatasi krisis yang dialaminya sebagaimana tahap perkembangan psikososial.

Penelitian-penelitian pada paragraf sebelumnya telah membahas tentang school well-being pada usia SD dan SMP, sedangkan penelitian ini lebih menitikberatkan school well-being pada jenjang sekolah siswa SD dan SMP yang saat ini menjalankan sistem pendidikan full-day di Indonesia dikarenakan mengikuti peraturan dan kebijakan kementerian pendidikan dan kebudayaan Indonesia. Pada penerapan peraturan tersebut kesejahteraan siswa di sekolah perlu diperhatikan. Penelitian ini bertujuan dapat memberikan informasi berupa data kepada pihak yang terkait tentang pentingnya school well-being pada siswa di sekolah, sehingga kedepannya siswa dapat sejahtera di sekolah dengan dilakukan intervensi berupa layanan konseling pada siswa secara berkelanjutan pada jenjang SD maupun SMP.

\section{METODE}

Penelitian ini menggunakan metode kuantitatif korelasional. Populasi dalam penelitian ini merupakan siswa SD kelas empat dan lima, serta siswa SMP kelas tujuh dan delapan yang telah menerapkan sistem full day school dikarenakan mengikuti peraturan kebijakan dari kementerian pendidikan dan kebudayaan Indonesia. Teknik sampling yang digunakan adalah accidental sampling. Sampel pada penelitian ini berjumlah 560 yang terdiri dari 285 siswa SD dan 275 siswa SMP.

Prosedur penelitian ini melalui tiga tahapan. Tahap pertama, persiapan berupa alat ukur school wellbeing yang disebut dengan School Well-being Profile (SWP) (Konu \& Koivisto, 2011) dengan empat dimensi berupa having, loving, being dan health, yang telah diadaptasi dalam bahasa Indonesia yang mengacu pada konsep dari Beaton, Bombardier, Guillemin, \& Ferraz, (2000). Kuesioner SWP siswa SD sejumlah 57 butir pernyataan dengan rentang skala 0-2, 0 (Tidak Setuju), 1 (Netral), 2 (Setuju) salah satu contoh butir pernyataan loving adalah: "teman sekelas saling membantu dalam setiap permasalahan", sedangkan kuesioner SWP siswa SMP sejumlah 81 butir pernyataan dengan rentang skala 0-4, 0 (Sangat Tidak Setuju), 1 (Tidak Setuju), 2 (Netral), 3 (Setuju), dan 4 (Sangat Setuju) salah satu contoh butir pernyataan loving adalah "kerja kelompok di kelas saya berjalan dengan baik".

Selanjutnya dilakukan uji reliabilitas pada kedua kelompok. SWP untuk siswa SD memiliki nilai konsistensi internal yang diukur melalui Cronbach's Alpha sebesar 0,868. Nilai Cronbach's Alpha masing-masing dimensi yaitu: having sebesar 0,792; loving sebesar 0,720; being sebesar 0,555; health sebesar 0,763. Sedangkan SWP siswa SMP memiliki nilai konsistensi internal yang diukur melalui Cronbach's Alpha sebesar 0,974. Nilai Cronbach's Alpha masing-masing dimensi yaitu: having sebesar 0,945; loving sebesar 0,960; being sebesar 0,952; health sebesar 0,715. Berdasarkan hasil tersebut, dapat diketahui bahwa skala versi adaptasi ini masih memiliki nilai reliabilitas yang tinggi dan layak untuk digunakan.

Tahap kedua, pengambilan data penelitian dilakukan pada sekolah SD dan SMP yang menjalankan sistem full-day, selanjutnya dilakukan uji asumsi normalitas dan homogenitas. Data normalitas pada kelompok siswa SD memiliki $p$-value sebesar 0,08989 (p-value >0,05), dan data kelompok siswa SMP 
memiliki $p$-value sebesar 0,08025 ( $p$-value $>0,05$ ), sehingga dapat dikatakan data terdistribusi normal. Uji homogenitas melalui Levene's Test pada data dari kelompok siswa SD dan siswa SMP menunjukkan $p$-value sebesar 0,8702 ( $p$-value $>0,05$ ) bahwa data dikatakan homogen;

Tahap ketiga, analisis data dilakukan dengan menggunakan tes statistik parametrik $t$-test sesuai dengan hasil uji normalitas dan homogenitas data yang telah dikumpulkan. Jenis $t$-test yang digunakan adalah independent two-sample t-test dengan metode Welch's t-test. Peneliti menggunakan Welch's $\mathrm{t}$-test karena varians dari kedua kelompok yang diteliti berbeda. Analisis ini dilakukan dengan tahap menggunakan aplikasi R studio versi 3.3.2.

\section{HASIL}

Hasil penelitian ini akan memaparkan nilai persentase kategorisasi data SWP di antara dua kelompok yaitu siswa SD dan SMP yang menerapkan sistem full-day. Sebaran data kelompok siswa SD dan siswa SMP dalam hal school well-being memiliki persentase yang cukup berbeda setelah dikategorisasikan. Data school well-being kelompok siswa SD berkumpul pada kategori tinggi sebesar 12,9\% dan 87,01\% kategori sangat tinggi, sedangkan data school well-being kelompok siswa SMP sedikit lebih tersebar yaitu kategori rendah 6,9\%, kategori sedang 33,09\%, kategori tinggi 51,27\%, kategori sangat tinggi $8,7 \%$.

Analisis data dengan menggunakan Welch's t-test dilakukan untuk mengetahui apakah terdapat perbedaan school well-being pada siswa SD dan siswa SMP full day. Hasil analisis menghasilkan $p$-value $<0,001(\mathrm{p}<0,05)$ yang berarti terdapat perbedaan school well-being pada siswa SD dan SMP full day.

Analisis tambahan dilakukan dengan melakukan uji beda (Welch's t-test) terhadap masing-masing dimensi school well-being (having, loving, being, health) pada kelompok SD dan SMP. Hasil analisis tambahan disajikan pada tabel 1 . Mean secara keseluruhan dan masing-masing dimensi digunakan untuk melihat bagaimana kelompok SD dan SMP menilai school well-being. Terlihat bahwa dimensi pada setiap school well-being siswa SD lebih tinggi daripada siswa SMP, hal ini menunjukkan bahwa kebutuhan kesejahteraan siswa SD di sekolah dinilai lebih terpenuhi dibandingkan siswa SMP, yang mana kesejahteraan di sekolah siswa SD dapat meliputi lingkungan fisik sekolah, lingkungan belajar, dan pelayanan (having); hubungan sosial yang mengarah pada lingkungan sosial dalam belajar, hubungan antara siswa dan guru, hubungan antar teman sekolah, dinamika kelompok, bullying, serta kerja sama antara sekolah dan rumah (loving); kebutuhan memenuhi diri sendiri dan penghargaan (being); status kesehatan siswa ditinjau dari gejala fisik dan mental (health).

Tabel 1. Hasil Analisis Tambahan

\begin{tabular}{lccccc}
\hline & School Well-being & \multicolumn{4}{c}{ Dimensi } \\
\cline { 3 - 6 } & & Having & Loving & Being & Health \\
\hline p-value & 0,001 & 0,001 & 0,001 & 0,001 & 0,001 \\
Mean SD & 3,8702 & 3,8386 & 3,9018 & 3,9439 & 1,3825 \\
Mean SMP & 2,6182 & 2,6836 & 3,0109 & 2,6763 & 1,8764 \\
\hline
\end{tabular}

\section{PEMBAHASAN}

Hasil penelitian ini menunjukkan bahwa terdapat perbedaan school well-being pada siswa SD full day dan siswa SMP full day, dimana siswa SD memiliki well-being yang lebih tinggi daripada siswa SMP. Penelitian lain juga menunjukkan bahwa terdapat perbedaan school well-being pada siswa SD dan siswa SMP, dimana siswa SD memiliki school well-being yang lebih baik daripada siswa SMP (Konu \& Lintonen, 2006). Di sekolah, secara umum siswa yang lebih muda menunjukkan well-being lebih tinggi daripada siswa yang lebih tua (Løhre, Lydersen, \& Vatten, 2010). Sebuah penelitian menunjukkan bahwa school well-being siswa SD berprestasi yang bersekolah di sekolah full-day school cukup baik dikarenakan siswa dapat beradaptasi dengan baik sehingga merasa sejahtera di sekolah (Faizah, Prinanda, Rahma, \& Dara, 2018). 
School well-being pada siswa di sekolah merupakan indikator penting dari kualitas yang baik di sebuah institusi pendidikan (Liu, Tian, Huebner, Zheng, \& Li, 2015). Hal ini dapat kita ketahui berdasarkan penilaian siswa SD bahwa kebutuhan kesejahteraan siswa SD di sekolah masih terpenuhi dengan baik selain karena karakter diri siswa, juga karena adanya dukungan dari lingkungan sekolah yang masih memberikan perhatian pada siswa SD dalam proses pembelajaran di sekolah.

Peneliti juga melakukan uji beda pada masing-masing dimensi dengan hasil berupa $p$-value dari dimensi tersebut yang menunjukkan adanya perbedaan yang signifikan pada semua dimensi, dimana dimensi school well-being siswa SMP lebih rendah daripada siswa SD. Minimnya kesejahteraan psikologis remaja, dapat disebabkan karena rendahnya personal growth yang dimiliki siswa sebagai remaja. Hal ini dapat dimungkinkan karena remaja merasa stagnan di situasi tertentu, bosan dan tidak tertarik dengan hidup, merasa tidak mampu untuk membangun sikap dan perilaku yang baru (Prabowo, 2016).

Perbedaan school well-being pada siswa SD dan SMP juga dipengaruhi karena dukungan sosial sekitar. Hal ini berkaitan dengan perbedaan yang signifikan pada siswa SD dan SMP pada dimensi loving. Terdapat tiga aspek penting dari dukungan sosial terhadap school well-being, yaitu dukungan dari guru, teman sebaya dan juga orangtua. School well-being akan menjadi baik apabila seorang siswa mendapatkan dukungan-dukungan tersebut (Tian, Liu, Huang, \& Huebner, 2013). Hal ini sebenarnya memberikan sinyal pada lingkungan sosial siswa (guru, teman sebaya, orangtua) agar tetap memberikan interaksi yang selaras dalam pemenuhan kebutuhan diri untuk dapat sejahtera di sekolah baik di jenjang SD maupun SMP, tanpa pilih kasih dikarenakan usia ataupun jenjang sekolah yang dilalui siswa.

Hubungan guru-murid merupakan bagian dari loving yang menjelaskan bagaimana kepuasan siswa terhadap relasi yang terjalin dengan guru mereka. Ketika siswa menemukan kesulitan dalam belajar, maka bantuan dan keterbukaan dari para guru akan membuat siswa menjadi lebih puas terhadap kehidupan sekolahnya (Wijayanti \& Sulistiobudi, 2018). Siswa mendapatkan keuntungan dari hubungan positif dengan guru. Semakin positif hubungan antara siswa dengan guru, maka akan meningkatkan ikatan antara siswa dan guru sehingga meningkatkan tingkat keterlibatan siswa dalam proses pembelajaran (Hughes \& Kwok, 2007). Hubungan antara guru dengan siswa dapat memengaruhi prestasi akademik siswa (McCormick \& O’Connor, 2015; Tennant et al., 2015).

Selain dukungan guru, well-being siswa di sekolah juga membutuhkan dukungan teman sebaya (peer relation). Peer relation dalam hal loving memiliki peran paling besar pada aspek perasaan siswa. Siswa dengan well-being yang tinggi, salah satunya disebabkan keterbukaan dalam menjalin persahabatan, mengajak teman-temannya berbincang-bincang, bercanda, tersenyum dan menyebarkan aura positif. Peer relation pada siswa, secara signifikan dapat memprediksi perasaan tidak menyenangkan dengan situasi di sekolah. Ketika relasi pertemanan sebaya para murid sekolah dasar berlangsung dengan terbuka, mereka memiliki banyak teman, dapat melakukan aktivitas bermain bersama. Hal ini akan meminimalisir munculnya perasaan negatif terhadap situasi sekolah. Sebaliknya, ketika siswa terabaikan secara sosial di sekolah, tidak memiliki teman, tidak banyak bermain dan bersosialisasi secara terbuka dengan rekanrekannya maka dapat diprediksi munculnya perasaan sedih (Wijayanti \& Sulistiobudi, 2018). Bahkan dalam latar akademik, sebuah penelitian menunjukkan kebahagiaan seorang siswa dipengaruhi oleh kebahagiaan teman sekelas mereka (King \& Datu, 2017). Teman sebaya yang hubungannya positif dalam pertemanan, memiliki peranan yang sangat penting dalam membangun kesejahteraan siswa di $\mathrm{SD}$, sehingga akan memengaruhi pola pikir dan sikap siswa dalam pertemanan.

Penelitian lain mengungkapkan bahwa orangtua dan teman sebaya dapat menimbulkan konflik pada remaja. Konflik ini yang menyebabkan school well-being siswa menjadi rendah atau buruk. Berdasarkan perkembangan remaja, mereka merasa bahwa hubungan teman sebaya sangat penting dan cenderung mulai mandiri dan mengurangi waktu bersama dengan orangtua dalam mencari identitas diri (Santrock, 2012). Hal ini terkadang menciptakan konflik bagi siswa mengenai orangtua dan teman sebaya sehingga membuat school well-being siswa golongan remaja menjadi berbeda dibandingkan dengan school wellbeing pada siswa yang masih dalam tahapan anak-anak (Tian et al., 2013).

Perbedaan antara masa anak dan remaja dalam hal kesejahteraan psikologis di sekolah salah satunya adalah dalam dimensi having. Having dapat berupa mata pelajaran, dimana mata pelajaran yang dipelajari oleh siswa SD lebih sedikit daripada siswa SMP. Biasanya hanya satu atau beberapa guru yang mengajar banyak mata pelajaran di satu kelas pada suatu SD, berbeda dengan SMP dimana satu mata 
pelajaran diajar oleh satu guru (Konu \& Lintonen, 2006). Having juga dapat berupa suasana di kelas, sebuah kelas dimana kebanyakan siswa memiliki well-being yang tinggi, akan memunculkan iklim kelas yang positif, demikian pula sebaliknya (King \& Datu, 2017). Komponen kuantitas kurikulum serta beban tugas siswa yang terlalu tinggi dan banyak, juga perhatian guru dalam mengajar semakin menurun saat usia anak semakin besar atau jenjang sekolah semakin tinggi, hal ini cenderung tidak memberikan pemenuhan kebutuhan kesejahteraan pada siswa khususnya siswa SMP. Siswa SD maupun SMP tetap membutuhkan ruang gerak dan kesempatan yang sama dengan meminimalisir beban tugas dan tetap memberikan suasana kelas yang menyenangkan sesuai usia.

Pada school well-being, dimensi being berhubungan lebih kuat dengan loving meskipun semua dimensi memiliki hubungan satu dengan lainnya (Konu \& Rimpelä, 2002). Peer acceptance adalah tahapan perkembangan yang penting pada masa remaja awal, karena hal ini berkaitan dengan well-being pada remaja, resiliensi, dan kesuksesan di sekolah maupun di luar sekolah (Oberle \& Schonert-Reichl, 2013; Thomson, Schonert-Reichl, \& Oberle, 2015; Wentzel, Barry, \& Caldwell, 2004). Sebagai remaja, siswa SMP sangat penting untuk melakukan pemenuhan diri, di mana siswa dapat mengeksplorasi perannya dalam lingkungan dan diapresiasi. Hal ini berpengaruh terhadap permasalahan yang dihadapi remaja, yaitu krisis identitas (Santrock, 2012). Aspek ini berkaitan erat dengan loving, yang mengindikasikan bahwa dukungan sosial dari lingkungan akan berperan dalam pemenuhan kebutuhan diri dalam kesejahteraan siswa, sehingga siswa SMP yang memasuki masa transisi anak ke remaja tetap membutuhkan support secara penuh dari lingkungannya.

Siswa SMP yang memasuki masa remaja juga memasuki masa storm and stress, yang artinya remaja lebih rentan terhadap stres (Yusuf, 2004). Selain itu, tuntutan yang lebih besar pada siswa SMP dibandingkan siswa SD, menyebabkan siswa SMP menjadi lebih mudah lelah secara fisik dan mental. Meskipun demikian, secara fisik Siswa SMP memiliki sistem kekebalan tubuh yang lebih baik daripada Siswa SD. Hal ini yang memengaruhi perbedaan school well-being dari segi dimensi health. Kondisi health dalam hal mental seperti ketegangan diri, rasa takut, semangat rendah lebih cenderung terlihat pada siswa SMP jika tuntutan yang mereka hadapi tidak terselesaikan dengan baik.

Data penelitian ini dapat dijadikan acuan bagi pemangku kebijakan dan konselor sekolah tentang pentingnya school well-being siswa, khususnya perhatian terhadap siswa SMP yang sedang menghadapi masa transisi. Layanan konseling yang lebih sistematis dan berkelanjutan dalam hal permasalahan akademik maupun non-akademik sebaiknya ditingkatkan. Hasil Penelitian ini hanya menyajikan dalam tataran data kondisi school well-being yang ada di lapangan pada siswa SD dan SMP yang menjalankan sistem full-day, peneliti selanjutnya dapat melakukan penelitian replikasi school well-being dengan sistem pendidikan yang berbeda maupun pada jenjang pendidikan lain yang ada di Indonesia. Begitu juga, peneliti selanjutnya dapat melakukan penelitian model intervensi layanan konseling kepada siswa SD maupun SMP dengan mempertimbangkan data hasil penelitian ini.

\section{SIMPULAN}

Berdasarkan penelitian yang telah dilakukan, school well-being siswa SD lebih tinggi daripada siswa SMP yang menjalankan sistem full day. Peneliti selanjutnya diharapkan untuk menggali dan mengolah data lebih jauh, terkait dengan perbedaan gender, usia, dan masing-masing tingkatan kelas di sekolah. Dengan diimplemantasikannya sistem full day, penyedia layanan pendidikan sebaiknya mempertimbangkan adanya perbedaan school well-being agar layanan di lingkungan sekolah seperti layanan konseling dapat dilakukan sesuai jenjang pendidikan dengan mempertimbangakan faktor-faktor yang memengaruhinya.

\section{DAFTAR RUJUKAN}

Beaton, D. E., Bombardier, C., Guillemin, F., \& Ferraz, M. B. (2000). Guidelines for the process of cross-cultural adaptation of self-report measures. Spine, 25(24), 3186-3191.

Ben-Aryeh, A., Casas, F., Frønes, I., \& Korbin, J. E. (2014). Handbook of child well-being: Theories, methods and policies in global perspective. Springer.

Danil, M. (2018). Implementasi full day school di Sekolah Dasar Sabbihisma Padang. Jurnal Komunikasi Pendidikan, 2(1), 86-92. 
Durán-Narucki, V. (2008). School building condition, school attendance, and academic achievement in New York City public schools: A mediation model. Journal of Environmental Psychology, 28(3), 278-286.

Faizah, F., Prinanda, J. N., Rahma, U., \& Dara, Y. P. (2018). School well-being pada siswa berprestasi sekolah dasar yang melaksanakan program penguatan pendidikan karakter. Psympathic: Jurnal Ilmiah Psikologi, $5(2), 161-174$.

Hughes, J., \& Kwok, O. (2007). Influence of student-teacher and parent-teacher relationships on lower achieving readers' engagement and achievement in the primary grades. Journal of Educational Psychology, 99(1), 3951.

Indahri, Y. (2017). Kebijakan lima hari sekolah. Majalah Info Singkat Kesejahteraan Sosial, 9, 9-12.

Kartika, E., \& Herawati, N. I. (2012). Karakteristik Perkembangan Sosial Emosi Siswa SD Laboratorium UPI Kampus Cibiru Dikaitkan Dengan Sistem Pembelajaran Full Day School. EduHumaniora| Jurnal Pendidikan Dasar Kampus Cibiru, 1(1).

King, R. B., \& Datu, J. A. (2017). Happy classes make happy students: Classmates' well-being predicts individual student well-being. Journal of School Psychology, 65, 116-128.

Konu, A., \& Rimpelä, M. (2002). Well-being in schools: a conceptual model. Health Promotion International, 17(1), 79-87.

Konu, A I, \& Koivisto, A.-M. (2011). The School Well-Being Profile-a valid instrument for evaluation. In Proceedings in EDULEARN11 Conference (pp. 4-6).

Konu, Anne I, \& Lintonen, T. P. (2006). School well-being in Grades 4-12. Health Education Research, 21(5), 633-642.

Liu, W., Tian, L., Huebner, E. S., Zheng, X., \& Li, Z. (2015). Preliminary development of the elementary school students' subjective well-being in school scale. Social Indicators Research, 120(3), 917-937.

Løhre, A., Lydersen, S., \& Vatten, L. J. (2010). School wellbeing among children in grades 1-10. BMC Public Health, 10(1), 526.

Macnow, A. S. (2017). MCAT Behavioral Sciences Review. Simon and Schuster.

McCormick, M. P., \& O'Connor, E. E. (2015). Teacher-child relationship quality and academic achievement in elementary school: Does gender matter? Journal of Educational Psychology, 107(2), 502.

Oberle, E., \& Schonert-Reichl, K. A. (2013). Relations among peer acceptance, inhibitory control, and math achievement in early adolescence. Journal of Applied Developmental Psychology, 34(1), 45-51.

Prabowo, A. (2016). Kesejahteraan psikologis remaja di sekolah. Jurnal Ilmiah Psikologi Terapan, 4(2), 246-260.

Rosalina, T. (2012). Pengaruh manajemen pembelajaran full day school terhadap motivasi belajar. Manajemen Pendidikan, 23(6), 434-435.

Sahari, S. (2018). Fullday school dalam sorotan ilmu sosiologi, psikologi, dan ekonomi. Jurnal Ilmiah Iqra', 11(1).

Santrock, J. W. (2012). Life-span development. University of Texas. Dallas: Mc Graw-Hill.

Soapatty, L., \& Suwanda, T. (2014). Pengaruh sistem sekolah sehari penuh (full day school) terhadap prestasi akademik siswa SMP Jati Agung Sidoarjo. Kajian Moral dan Kewarganegaraan, 2(2), 717-733.

Susilawati, D. (2014). Waktu belajar yang terlalu panjang sebabkan stress di anak. Retrieved from republika. co.id: http://republika.co.id/berita/humaira/ibu-anak/14/04/02/n3e5o6-waktu-belajar-yang-terlalu-panjangsebabkan-stress-di-anak

Tennant, J. E., Demaray, M. K., Malecki, C. K., Terry, M. N., Clary, M., \& Elzinga, N. (2015). Students' ratings of teacher support and academic and social-emotional well-being. School Psychology Quarterly, 30(4), 494.

Tharani, A., Husain, Y., \& Warwick, I. (2017). Learning environment and emotional well-being: A qualitative study of undergraduate nursing students. Nurse Education Today, 59, 82-87.

Thomson, K. C., Schonert-Reichl, K. A., \& Oberle, E. (2015). Optimism in early adolescence: Relations to individual characteristics and ecological assets in families, schools, and neighborhoods. Journal of Happiness Studies, 16(4), 889-913.

Tian, L., Liu, B., Huang, S., \& Huebner, E. S. (2013). Perceived social support and school well-being among Chinese early and middle adolescents: The mediational role of self-esteem. Social Indicators Research, 113(3), 991-1008.

Wentzel, K. R., Barry, C. M., \& Caldwell, K. A. (2004). Friendships in middle school: Influences on motivation and school adjustment. Journal of Educational Psychology, 96(2), 195-203. 
Wijayanti, P. A. K., \& Sulistiobudi, R. A. (2018). Peer relation sebagai prediktor utama school well-being siswa sekolah dasar. Jurnal Psikologi, 17(1), 56.

Yusuf, S. (2004). Psikologi perkembangan anak dan remaja. Bandung: Remaja Rosdakarya. 